\title{
APL ALIMENTOS
}

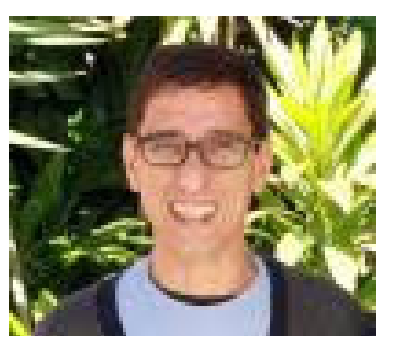

Daniel Marques Aquini: Mestre em Sociologia pela Universidade Federal de Pelotas (2015). É especialista em Projetos Sociais e Culturais: coordenação e avaliação pela Universidade Federal do Rio Grande do Sul (2002). Possui graduação em Direito pela Universidade Federal de Pelotas (1992). Atualmente é analista da Empresa Brasileira de Pesquisa Agropecuária - Embrapa - em seu Centro de Pesquisa Agropecuária de Clima Temperado, atuando no Setor de Prospecção e Avaliação de Tecnologias.

\section{ENTREVISTADOR:}

Felipe Fehlberg Herrmann: Possui graduação em Matemática pela Universidade Católica de Pelotas (2004), graduação em Administração de Empresa pela Universidade Católica de Pelotas (2010) mestrado em Engenharia de Produção pela Universidade do Vale do Rio dos Sinos (2012). Doutorando em Engenharia de Produção e Sistemas pela Universidade do Vale do Rio dos Sinos.Coordenador do Núcleo de Extensão e Pesquisa em Desenvolvimento Territorial (2014 - 2017). Coordenador do Plano de Desenvolvimento do APL Alimentos (2015 - 2017). Atualmente exerce o cargo de Coordenador de Extensão e Desenvolvimento Social junto a Pró-reitora de Extensão e Cultura da Universidade Federal de Pelotas. 


\title{
RESUMO
}

Os Arranjos Produtivos Locais (APLs) são articulações entre empresas, trabalhadores, governos e instituições científicas e tecnológicas (ICTs). Eles reforçam vínculos de produção, interação e aprendizagem, em um determinado território, com o objetivo de alcançar patamares superiores de desenvolvimento.O Arranjo Produtivo Local (APL) de Alimentos está situado na região Zona Sul do estado do Rio Grande do Sul e foca-se no processamento de frutas e hortaliças, mel e condimentos.

Palavras-chave: Arranjo produtivo localde alimentos. Agroindústrias. Região Sul do RS.

\begin{abstract}
Local Productive Arrangements (LPA) are articulations between companies, workers, governments and scientific and technological institutions (ICTs). They reinforce links of production, interaction and learning in a given territory, with the objective of reaching higher levels of development. The Local Productive Arrangement for Food is located in the Southern Zone of the state of Rio Grande do Sul and focuses on the processing of fruits and vegetables, honey and condiments.
\end{abstract}

Keywords: Local food productive arrangement. Agroindustries. South Region of RS.

\section{COMO SURGIU O APL ALIMENTOS DA REGIÃO SUL DO ESTADO RS?}

Os arranjos produtivos existem antes mesmo do reconhecimento pelos governos que constroem políticas públicas em seus benefícios. A produção de alimentos no sul do estadosurgiu com a própria ocupação do território, beneficiada, depois, por um processo de imigração de diversas etnias que se somaram aos portugueses e africanos. Desde então se aprofundaram as relações dos agentes sociais sendo paulatinamente construídos espaços que facilitaram sua articulação. Sindicatos, movimentos sociais, conselhos de desenvolvimento 
e outros cumpriram, e ainda cumprem, este papel. A eles somou-se o APL, desde 2013, com o apoio do Programa de Fortalecimento das Cadeias e Arranjos Produtivos Locais de acordo com a Lei Estadual $n^{\circ}$ 13.839/2011, do Estado do Rio Grande do Sul. As instituições locais submeteram uma proposta de APL à Edital Público que de pronto foi aprovada.

\section{QUAL(IS) O(S) OBJETIVO (S) NORTEADORES DO APL ALIMENTOS?}

De forma sucinta, contribuir para o desenvolvimento territorial, a preservação do conhecimento, valorização dos produtores, agregação de renda, laços de cooperação e confiança e, ainda, a participação nas decisões.

\section{QUANTAS EMPRESAS FAZEM PARTE DO APL ALIMENTOS E QUAL O PERFIL DESSAS EMPRESAS?}

Aderiram formalmente ao APL sessenta e quatro agroindústrias, cooperativas e associações de produtores. São empreendimentos dos mais variados portes e com um portfólio de produtos muito amplo. As indústrias de conserva, filiadas ao Sindocopel, são as maiores, no entanto, o maior número é de empreendimentos vinculados à agricultura familiar. Produzem mel, temperos, produtos à base de pimenta, doces, sucos, panificados, queijos, minimamente processados e embutidos de excelente qualidade. Nas feiras comercializam também produtos in naturarecém-colhidos garantindo à população de nossas cidades um alimento saboroso e nutritivo.

\section{QUAIS SÃO OS PRINCIPAIS BENEFÍCIOS PARA AS EMPRESAS ORGANIZADAS NO FORMATO DE APL?}

A criação e consolidação do APL contribuem para a formulação de modelos e experiências de gestão social do território. Isso é particularmente importante para a constituição de um processo de desenvolvimento social em bases sustentáveis e participativas. Assim, o APL constitui-se em um espaço privilegiado 
de cooperação e intercâmbio de conhecimentos entre os empreendimentos, as ICTs e o poder público local. Neste espaço se pode refinar as políticas, captar demandas, atualizar a agenda de P,D\&l das instituições, integrar ações e fortalecer sentimentos de confiança entre os agentes sociais. Outro aspecto importante a se destacar é o aumento da competitividade das agroindústrias locais na medida em que são compartilhados conhecimentos e recursos humanos e financeiros por meio da atuação em rede. Uma melhor articulação entre a oferta e demanda de alimentos nas compras institucionais está proporcionando um aumento da renda das famílias beneficiadas, principalmente aquelas vinculadas às cooperativas e associações. Vale destacar, também, o fortalecimento das cadeias curtas de comercialização, por meio da criação de novos espaços de comercialização, participação em feiras livres e eventos, aos moldes das Feiras da Agricultura Familiar, que proporcionam um contato direto dos produtores com os consumidores. Isso reduz a importância de terceiros nas cadeias de valor, fortalece a identidade dos produtores e seu conhecimento tradicional e garante um alimento mais saudável para a população.

\section{QUAIS SÃO AS INSTITUIÇÕES PARCEIRAS DO APL ALIMENTOS?}

O APL Alimentos da Região Sul do RS, atua desde 2013, em regime de confiança e colaboração - com foco no processamento de frutas, hortaliças, mel e condimentos - constituindo uma extensa rede de apoiadores, com destaque para assessenta e quatroagroindústrias que aderiram ao projeto e às instituições que compõem a governança doarranjo (universidades, centros de pesquisa, ONGs, cooperativas, entre outras). Além destas, as ações também contaram com o apoio do Governo do Estado do RS, das Prefeituras de Pelotas, Rio Grande, Canguçu e Morro Redondo, da Associação dos Municípios da Zona Sul (Azonasul), do Conselho Regional de Desenvolvimento da Região Sul (Corede-Sul), demais APLs da Região, movimentos sociais, entre outros.

\section{QUAIS FORAM OS AVANÇOS OBTIDOS PARA AS ORGANIZAÇÕES PARTICIPANTES DO APL ALIMENTOS?}

Em 2017 a Governança do APL priorizou o fortalecimento dos circuitos curtos de comercialização. Assim, ampliou-se a comercialização direta das 
cooperativas e agroindústrias por meio do PAA Compras Institucionais. Em 2014 foram comercializados $\mathrm{R} \$ 896.914 .16 ; 2015 \mathrm{R} \$ 1.379 .162,15 \mathrm{em} 2016 \mathrm{R} \$ 1.583 .664,35$ e em 2017 R $\$ 3.114 .435,75$. Também a comercialização em eventos foi expressiva. Somente na Fenadoce e Expoferira de Pelotas foram comercializados RS $638.016,44$. Esses resultados são bastante significativos para as cerca demil famílias beneficiárias. Também em 2017 concluiu-se o processo de georeferenciamento dos empreendimentos, localizando-os no mapa e agregando informações relevantes aos clientes tais como histórico dos empreendimentos, contatos, produtos, fotos, como chegar, participação em roteiros turísticos entre outras, contribuindo para comercialização dos produtos (dados disponíveis no site www.aplalimentosul. org.br). Os Pontos de Comercialização (PCs) foram incrementados a exemplo da Casa da Pimenta no município de Turuçu, que disponibiliza cerca de duzentos diferentes produtos ao mercado, e a Banca 78 do Mercado Central de Pelotas, que comercializa produtos de vinte e duas cooperativas e agroindústrias familiares. Note-se que a implementação e/ou consolidação dos circuitos curtos, para além do aumento da renda dos agricultores gerada pela diminuição de processos e agentes intermediários, promove uma integração positiva entre os agricultores e os cidadãos/consumidores promovendo trocas de saberes, confiança quanto à qualidade dos produtos e sua procedência. Daí que, paralelamente a essas ações de comercialização, levou-se à cabo oficinas e visitas técnicas com a participação do Instituto Histórico e Artístico Nacional (IPHAN) com vistas ao início do processo de salvaguarda do conhecimento de famílias tradicionais na produção de doces coloniais. As ações do Arranjo - pode-se dizer - combinam tradição e inovação com o sentido de agregar valor e aumentar a capacidade produtiva das agroindústrias, gerando emprego, renda e desenvolvimento, beneficiando, direta ou indiretamente, mais de trinta e quatro mil famílias de agricultores familiares da região sul.

\section{COMO É REALIZADA A GESTÃO DO APL ALIMENTOS?}

O APL possui um comitê Gestor do qual o SINDOCOPEL, CAFSul, Cooperativa SulEcológica, CAPA, CONAPZ, Coafan, Fórum da Agricultura Familiar, IF-Sul, UFPel, FURG, Emater/RS, Fepagro e a Embrapa Clima Temperado. Em decorrência da implantação da Banca 78 no Mercado Central de Pelotas foram construídos mais dois espaços de gestão: a Assembleia da Banca e se Comitê gestor próprio. Orientam o trabalho de Gestão o Plano de Desenvolvimento do APL e as resoluções decorrentes de reuniões periódicas. 


\section{QUAIS FORAM OS PRINCIPAIS EVENTOS REALIZADOS E OS QUAIS O APL PARTICIPOU?}

Foram muitos os eventos que o APL organizou e participou. O APL promoveu rodadas de negócio, em parceria com o SEBRAE, aproximando as agroindústrias e produtores de restaurantes e hotéis da região, bem como realizou mesa de negociação com a Coca-Cola a fim de levantar demandas e aproximar as empresas locais produtoras de polpa da empresa haja vista o crescente incremento do setor de sucos. O arranjo organizou, conjuntamente com o Governo do Estado, a recepção de uma delegação francesa formada pela Agrauxine, Flerion D’Anjou, Florentaise, Goemar, Squau, Cesbron, Vegenov, UniversiteAvgnon, INRA, Ubifrance e Ubifrance Brasil, empresas e instituições vinculadas ao arranjo produtivo francês Vegepolys.

Entre os diversos eventos promovidos, ou que contaram com a participação do arranjo, destacaram-se o I Seminário de Desenvolvimento da Cadeia Produtiva Apícula da Região Sul, Seminário sobre Inspeção Sanitária, o Seminário Nova Legislação de Produtos Orgânicos e o Mercado de Alimentos e o II Seminário Aproximando a Agricultura Familiar do Mercado Institucional.

O APL organizou, também, Feiras da Agricultura Familiar durante a Festa Nacional do Doce de Pelotas (Fenadoce 2015, 2016 e 2017); Expofeiras de Pelotas 2014/2015/2016/2017 e Feira Estadual de Sementes Crioulas e Tecnologias Populares. Contribuiu, ainda, com a edição de dois Festivais de Gastronomia realizados em Pelotas.

\section{O APL ALIMENTOS TEM COLABORADO NO CUSTEIO E ORGANIZAÇÃO DE EVENTOS COMO A FEIRA DE SEMENTES, COMO O FORTALECIMENTO DO APL ALIMENTOS PODE CONTRIBUIR PARA UM DESENVOLVIMENTO SUSTENTÁVEL DA REGIÃO SUL DO ESTADO?}

Sim, o APL colabora na medida do possível. O segundo convênio firmado com o Governo do RS previa essa possibilidade. No momento discutese alternativas de novos projetos a serem apresentados para diversas fontes financiadoras para que se possa dar continuidade a esse tipo de ação. Penso que o APL Alimentos colabora com o desenvolvimento na medida em que se aprofundam os laços de cooperação entre os empreendimentos, fortalecendo- 
os econômica e socialmente. A experiência internacional mostra que a constituição de relações de proximidade, mais flexíveis e baseadas na confiança, colaboram para o estabelecimento de negócios com maior agilidade, redução de custos - principalmente logísticos - e consequente maior rentabilidade. A isso acrescentamos que, no modelo operado em nossa região, boa parte dos empreendimentos envolvem um enorme número de famílias, contribuindo para a diminuição das desigualdades e sua inclusão produtiva.

\section{QUAIS SÃO OS PRÓXIMOS DESAFIOS DO APL ALIMENTOS?}

Essa é uma discussão que se deve aprofundar nos próximos meses quando da realização do planejamento das ações do APL para o próximo período, lastreado no Plano de Desenvolvimento do arranjo. No entanto, alguns sinais já se puderam captar. Posso citar o aprimoramento da estratégia de fortalecimento dos circuitos curtos de comercialização, a ampliação da produção agroecológica e a ampliação do debate a respeito da construção social da qualidade dos produtos, fundamentalmente no que diz respeito aos seus aspectos regulatórios.

Data de recebimento: 10 de janeiro de 2018 .

Data de aceite para publicação: 10 de janeiro de 2018. 